\title{
An epileptic seizure and haemorrhage into the ventricular system of the brain as the first manifestations of acquired haemophilia A - Case report
}

\author{
Bożena Sokołowska ${ }^{1, A-D \oplus}$, Justyna Kozińska ${ }^{1, B-C \oplus}$, Dariusz Szczepanek ${ }^{2, B} \oplus$,

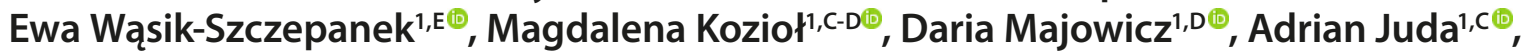 \\ Marek Hus, ${ }^{1, E-F} \odot$ \\ ${ }^{1}$ Department of Haematooncology and Bone Marrow Transplantation, Medical University, Lublin, Poland \\ ${ }^{2}$ Department of Neurosurgery and Pediatric Neurosurgery, Medical University, Lublin, Poland \\ A - Research concept and design, B - Collection and/or assembly of data, C - Data analysis and interpretation, \\ $D$ - Writing the article, E - Critical revision of the article, F-Final approval of the article
}

\begin{abstract}
Sokołowska B, Kozińska J, Szczepanek D, Wąsik - Szczepanek E, Kozioł M, Majowicz D, Juda A, Hus M. An epileptic seizure and haemorrhage into the ventricular system of the brain as the first manifestations of acquired haemophilia A - Case report. Ann Agric Environ Med. 2021; 28(3): 531-533. doi: 10.26444/aaem/140306

Abstract

Acquired haemophilia $(\mathrm{AH})$ is a suddenly occurring severe blood diathesis that affects both males and females and is caused by autoantibodies which inhibit coagulation factor VIII. The report describes an unusual case of acquired haemophilia in which an epileptic seizure and haemorrhage into the ventricular system of the brain were the first manifestations of the disease. In addition, APTT was prolonged to 94.6 seconds and the factor VIII level was as low as 1.5\%. The level of anti-FVIII antibody was extremely high - 272BU/ml. The patient did not undergo invasive diagnostic procedure or an operation. Recombinant factor VIla was used to control the bleeding. In order to eradicate the inhibitor, the patient received prednisone and cyclophosphamide. Complete remission was achieved after 5.5 weeks of treatment.
\end{abstract}

\section{Key words}

intracranial haemorrhage, haemophilia, factor VIII

\section{INTRODUCTION}

Acquired haemophilia (AH) is a suddenly occurring severe blood diathesis that affects both males and females. The most common manifestations of $\mathrm{AH}$ include extensive subcutaneous haemorrhages and intramuscular haematomas [1]. Intracranial haemorrhages are extremely rare, especially as the first manifestations of the disease $[2,3,4]$. AH may lead to death among $8-22 \%$ of patients. When there is a suspicion of $\mathrm{AH}$ in a patient with an acute and/or life-threatening bleeding after sampling for further tests, invasive procedures and surgeries should be withdrawn and proper treatment should be implemented, even if the test results are not yet available [5]. This information should be emphasized especially among the communities of neurologists and neurosurgeons since conventional angiogram, which is often indicated in the course of the diagnostic procedure for nontraumatic intracranial haematoma, may be dangerous in AH patients.

\section{OBJECTIVE}

The aim of the study is the presentation of an unusual case of acquired haemophilia in which an epileptic seizure and

\footnotetext{
Address for correspondence: Adrian Juda, Department of Haematooncology and Bone Marrow Transplantation, Medical University, Aleje Racławickie 1, 20-059 Lublin, Poland

E-mail: adrianjuda@op.pl

Received: 12.04.2021; accepted: 05.07.2021; first published: 10.09.2021
}

haemorrhage into the ventricular system of the brain were the first manifestations of the disease.

\section{CASE REPORT}

On 29 March 2014, a 57-year-old male was admitted to hospital because of a history of blackouts in obscure circumstances. Concomitant conditions included a history of cerebral infarction in the past, alcoholism and scabies. At the time of admission, physical examination showed disturbances of consciousness due to alcohol consumption. An increased concentration of ethyl acid in the serum was confirmed $(2.22 \%$, physiologic value $<0.2 \%$ o). Nevertheless, no signs of focal impairment of the central nervous system (CNS) were detected on neurological examination. Simultaneously, oedema and many subcutaneous haematomas of the left upper limb were present as well as eczema, caused by scratching in the course of scabies infection, was found all over the skin. During the first day of hospitalization, one episode of an epileptic seizure occurred. The patient received a diazepam injection, which gave a satisfactory result. During the diagnostic procedure, computed tomography (CT) of the brain revealed the presence of haemorrhage into the ventricular system around the septum pellucidum. No signs of the skull/head injury were found (Fig. 1).

During the second day of hospitalization, subcutaneous haematomas of the right upper limbs occurred. The first laboratory data revealed activated partial thromboplastin time (APTT) out of limit. The patient received 8 units of 


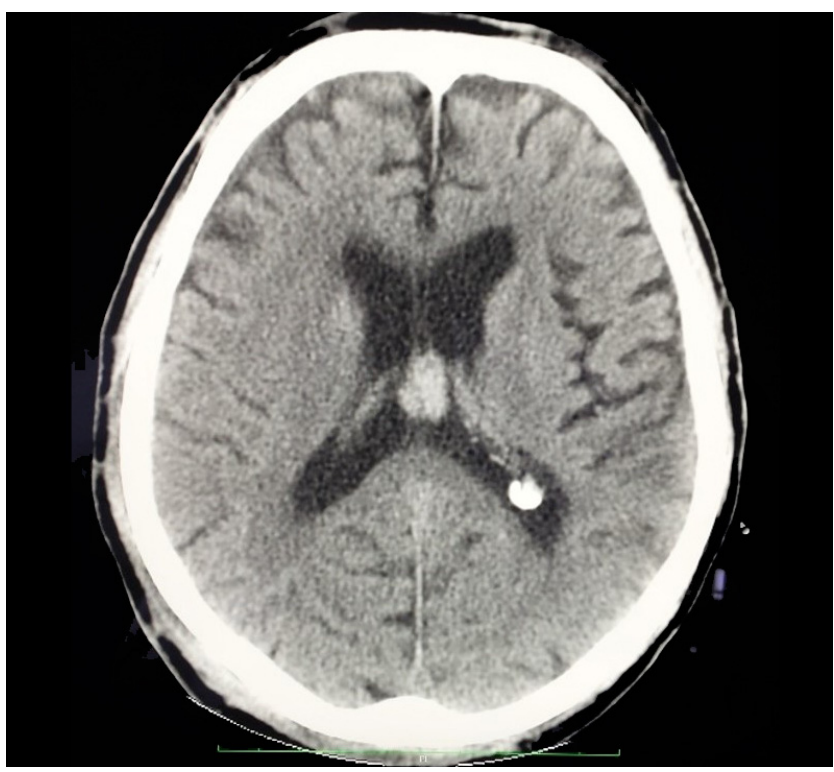

Figure 1. CT examination of the brain: hemorrhage into the ventricular system around the septum pellucidum

fresh frozen plasma (FFP) without any effect. Because of

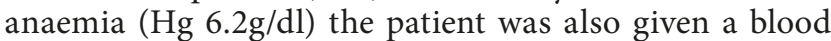
transfusion (2 units). As acquired haemophilia ( $\mathrm{AH})$ was suspected, profound laboratory diagnostics were performed. APTT was $94.6 \mathrm{sec}$, mixed studies showed lack of APTT correction, factor VIII level was as low as $1.5 \%$, and the presence of Anti-F VIII antibody was confirmed. The level of anti-FVIII antibody was extremely high, 272 Bethesda Units/ml. Recombinant factor VIIa was used to control the bleeding. First, the dosage was $8 \mathrm{mg}(90 \mathrm{ug} / \mathrm{bw})$ every 3 hours, after which the period between the drug administrations was extended. The treatment lasted 3 weeks and the total dose of rFVIIa was $227 \mathrm{mg}$.

To eradicate the inhibitor, the patient received prednisone and cyclophosphamide. The patient also tolerated haemostatic and immunosuppressive therapy very well. Complete remission was achieved after 5.5 weeks, even during the patient's hospital stay. The patient was discharged from hospital with the recommendation to take only prednisone at the initial dose of $30 \mathrm{mg}$ daily. The dose was then reduced by $5 \mathrm{mg}$ weekly, and after one month, immunosuppressive therapy was discontinued.

Two months later, in August 2014, the patient reported to the out-patient's clinic in a very good condition, without any visible haematomas. The APTT value was within normal limit. This was the patient's last check-up visit (Fig. 2).

\section{DISCUSSION}

Acquired Haemophilia (AH) has been estimated to develop among $0.2-1$ patient per 1 million inhabitants and is caused by autoantibodies (predominantly IgG1 and IgG4) which inhibit coagulation factor VIII [1]. Some polyclonal IgG antibodies, due to their proteolytic properties, are capable of hydrolyzing FVIII into smaller pieces. FVIII antigen is then endocytosed by antigen presenting cells which can stimulate B cells to produce FVIII-specific antibodies [6]. In $50 \%$ of cases, the disease is idiopathic. In the remaining cases, the disease is accompanied by autoimmune conditions,

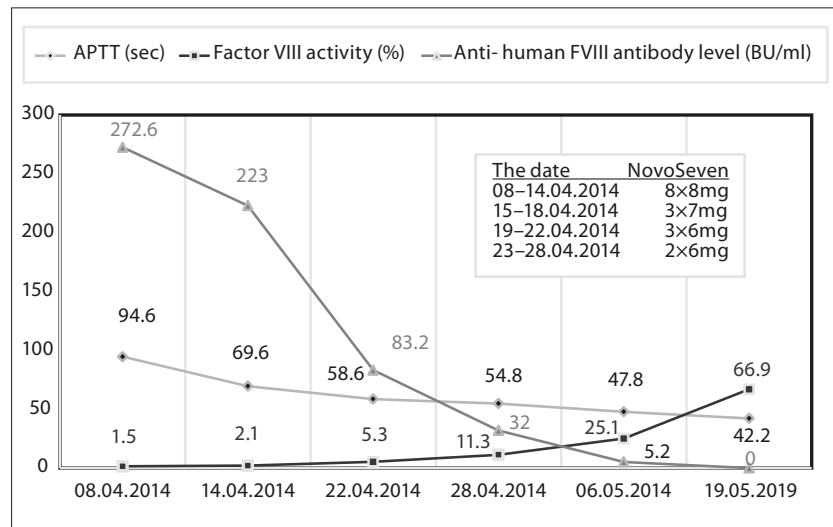

Figure 2. Coagulation parametrs during the time of observation

lymphoproliferation, neoplastic diseases, pregnancy or postpartum period, and infections, including SARS-CoV-2 infection $[7,8]$. In the patients presented so far, there have occurred only conditions which may be recognized as comorbidities, not underlying disorders; therefore, in the presented case the cause of $\mathrm{AH}$ might have been idiopathic. While CT of the brain revealed haemorrhage into the ventricular system and subcutaneosu haematomas were present on the upper limbs, a profound haemostatic diagnostics was performed. In the laboratory investigations, APTT was so significantly prolonged that it was not possible to determine the APTT value (out of limit). The consecutive evaluation revealed the APTT value of $94.6 \mathrm{sec}$. In many cases of AH, APTT is significantly prolonged, usually 2-3 fold [1]. Nevertheless, great caution is required since sometimes APTT in AH may be within normal limits. In 2016, Tsuyama described a case of a 73-year-old patient with intramuscular haematoma and cerebral haemorrhage whose APTT in the initial evaluation was normal [9]. Only repeated coagulation studies revealed an isolated prolongation of the APTT. If the coagulation studies had not been repeated, $\mathrm{AH}$ (a potentially life-threatening disorder) would not have been diagnosed.

Furthermore, avoidance of any invasive procedures during the diagnostics proved to be very important. Conventional angiography may cause unnecessary risk of bleeding in $\mathrm{AH}$ patients, therefore avoidance of angiography should be considered, especially if other vessel imaging is not suggestive of vascular malformations. In the patient presented, CT showed intracranial haemorrhage accompanied by coagulation abnormalities, therefore conventional angiography was not performed. Another crucial aspect is that the patient should not undergo an operation. In 2009, Mashiko et al. reported the case history of a 74-year-old man who was found comatose in his bed. CT revealed a massive subdural haematoma [10]. Among many laboratory evaluations only isolated prolonged APTT (77 seconds) was found. The patient underwent several operations because of repeated intracranial haematomas, receiving simultaneously FFP or factor VIII and factor IX concentrates. Despite the intensive treatment, the patient's general status deteriorated, the prolonged APTT value persisted, the activity of factor VIII was very low, and finally the patient died. Afterwards, information that the Factor VIII inhibitor was detected and the level of the inhibitor was high (46 Bethesda units/ml) emerged which confirmed the diagnosis of $\mathrm{AH}$ [8]. On the basis of the case history presented above, it seems that a better treatment option might be one of the bypassing 
agents (rFVIIa or aPCC) since Factor VIII concentrates are ineffective, especially in patients with higher than $5 \mathrm{BU}$ Factor VIII inhibitor [1]. On the other hand, it is known that the use of bypassing agents does not always guarantee success. In 2003 and 2006, 2 AH patients were reported who first presented intracranial haemorrhage. One of them showed good recovery with rFVIIa whereas the other died due to intracerebral rebleeding, despite having received FVIIa treatment $[11,12]$.

\section{CONCLUSIONS}

The situation presented above teaches us that in patients with no medical history of bleeding a sudden ocurrence of intracranial haemorrhage should arouse the suspicion of $\mathrm{AH}$, especially if isolated prolonged APTT is also found. Popularizing knowledge about this disease may contribute to shortening the diagnostic process, allowing us to choose the best treatment strategy which can cause remission and save a patient's life.

\section{REFERENCES}

1. Windyga J, Baran B, Odnoczko E, et al. Treatment guidelines for acquired haemophilia A.Ginekol Pol. 2019; 90(6): 353-364. doi: 10.5603/ GP.2019.0063
2. Charlebois J, Rivard GE, Str-Louis J. Management of acquired haemophilia A: Review of current evidence. Transfus Apher Sci. 2018; 57(6): 717-720. doi: 10.1016/j.transci.2018.10.011

3. Akamatsu Y, Hayashi T, Yamamoto J, et al. Newly diagnosed acquired haemophilia A manifesting as massive intracranial hemorrhage following a neurosurgical procedure. World Neurosurg. 2018; 111: 175-180. doi: 10.1016/j.wneu.2017.12.016

4. Sehara Y, Hayashi Y, Mimuro J. Acquired Haemophilia A with a rare presentation of acute subdural hematoma. Case Rep Neurol Med. 2015 2015: 543927. doi: 10.1155/2015/543927

5. Garcia-Chavez J, Majluf-Cruz A. Acquired haemophilia. Gac Med Mex. 2020; 156(1): 67-77. doi: 10.24875/GGM.19005469

6. Lan Mo, George C. Bao. Acquired factor VIII deficiency: two case report and a review of literature. Exp Hematol Oncol. 2017; 6(1): 8-8. doi: 10.1186/s40164-017-0068-3

7. Franchini M, Glingani C, De Donno G, et al. The first case of acquired haemophilia A associated with SARS-CoV-2 infection. Am J Hematol. 2020; 10.1002/ajh.25865. doi: 10.1002/ajh.25865

8. Mingot-Castellano ME, Nunez R, Rodriguez-Martorell FJ. Acquired haemophilia: Epidemiology, clinical presentation, diagnosis and treatment. Med Clin (Barc). 2017; 148(7): 314-322. doi: 10.1016/j. medcli.2016.11.030

9. Tsuyama N, Ichiba T, Naito H. Unusual Initial Manifestation of Acquired Haemophilia A: A normal Activated Partial Thromboplastin Time, intramuscular hematoma and cerebral hemorrhage. Intern Med. 2016; 55 (22): 3347-3349. doi: 10.2169/internalmedicine.55.7219

10. Mashiko R, Yamamoto T, Sato M, et al. A. Acquired haemophilia first manifesting as life-threatening intracranial hemorrhage-case report. Neurol Med Chir. 2009; 49: 93-95. doi: 10.2176/nmc.49.93

11. Bonnaud I, Saudeau D, de Toffol B, Autret A. Recurrence of spontaneous subdural haematoma revealing acquired haemophilia. Eur Neurol. 2003; 49(4): 253-254. doi: 10.1159/000070200

12. Marquardt L, Haubelt H, Gass S, et al. Intracranial bleeding in acquired haemophilia. Nervenarzt. 2006; 77(12): 1480-1482. doi: 10.1007/s00115006-2181-0 